DEMOGRAPHIC RESEARCH

VOLUME 34, ARTICLE 32, PAGES 899-926

PUBLISHED 1 JUNE 2016

http://www.demographic-research.org/Volumes/Vol34/32/

DOI: 10.4054/DemRes.2016.34.32

Research Article

Investigating the migrant mortality advantage at the intersections of social stratification in Switzerland: The role of vulnerability

\title{
Jonathan Zufferey
}

(C) 2016 Jonathan Zufferey.

This open-access work is published under the terms of the Creative Commons Attribution NonCommercial License 2.0 Germany, which permits use, reproduction \& distribution in any medium for non-commercial purposes, provided the original author(s) and source are given credit.

See http://creativecommons.org/licenses/by-nc/2.0/de/ 


\section{Table of Contents}

1 Introduction $\quad 900$

$2 \quad$ Data and methods 902

2.1 Data 902

2.2 Classification trees and modelling strategy 904

3 Results 908

3.1 The explanatory analysis 908

$\begin{array}{ll}3.2 & \text { The confirmatory analysis }\end{array}$

$4 \quad$ Discussion $\quad 917$

5 Acknowledgments 920

$\begin{array}{ll}\text { References } & 922\end{array}$ 


\title{
Investigating the migrant mortality advantage at the intersections of social stratification in Switzerland: The role of vulnerability
}

\author{
Jonathan Zufferey ${ }^{1}$
}

\begin{abstract}
BACKGROUND

Migrant mortality advantage has been widely studied in Western countries, but little attention has been paid to how social factors interact to increase or diminish risks of death. Socioeconomic factors are indeed widely used in regression models but mostly to define, ceteris paribus, whether migrants have a higher propensity to die than natives.
\end{abstract}

\section{OBJECTIVE}

Using an inductive approach, the aim of this paper is to reassess the role of social factors. Focusing on migrant communities, the paper establishes at which intersection of the components of social stratification the migrant mortality advantage is mainly located.

\section{METHODS}

This study is based on census data linked with population registers (2001-2008) and focuses on individuals aged 25-64 years living in Switzerland. It uses model-based regression trees to first map the structure of mortality risks within the social stratification. In a second step, a confirmatory analysis supports the main outcomes.

\section{RESULTS}

Inductive methods give substantial results, firstly in revealing interactions within the social structure. Secondly, the findings suggest that the mortality advantage is not located only among immigrants but encompasses a wide population with a foreign background. Thirdly, it demonstrates that the migrant mortality advantage is stronger in the most vulnerable profiles. The non-inclusion in previous research of the flatter mortality gradient among individuals with a foreign background tends to underestimate the strength of the differentials.

\footnotetext{
${ }^{1}$ University of Geneva, Switzerland. E-Mail: jonathan.zufferey@unige.ch.
} 


\section{CONCLUSION}

Selection and acculturation explanations are not sufficient to understand the migrant mortality advantage. Psychosocial factors related to the migration background may provide an alternative explanation.

\section{Introduction}

The migrant mortality advantage, also known as the migrant mortality paradox, has been widely studied in Western countries since it was observed for the first time about 30 years ago (Markides and Coreil 1986). The paradox is that mortality is lower among migrants than among natives, despite the lower socioeconomic status of the former compared to the latter. First studied in depth in the United States among the Hispanic populations (Markides and Eschbach 2005), the paradox has been revealed to be much more general, affecting almost all communities of immigrants in the country (Singh and Siahpush 2002). In Europe, researchers have found the same mortality advantage among diverse migrant populations (see, for example, Darmon and Khlat (2001) for France, Kohls (2010) for Germany, and Deboosere and Gadeyne (2005) for Belgium).

The greater longevity of migrants is challenging for scholars to decrypt. Many papers focus on establishing whether the observed mortality advantage is real; in other words, whether it can be explained by some direct or indirect factors, or can be accounted for by biases in data or measurement. There are in fact some important biases in selective migration, affecting both in-migration (the healthy migrant effect) and outmigration (Salmon bias) but they do not appear to be sufficient to explain the whole mortality advantage (Abraido-Lanza et al. 1999; Deboosere and Gadeyne 2005; Palloni and Arias 2004). A cultural interpretation arguing that migrants have better dietary habits, higher social support, and more favourable health behaviours is often added as a complementary explanation (Abraido-Lanza et al. 1999; Abraido-Lanza, Chao, and Flórez 2005; Markides and Coreil 1986).

This paper aims to rethink the role of social factors, disentangling how social forces interact within social stratifications to create mortality differentials. The key to the migrant mortality paradox is social position, located at the intersection of socioeconomic status and origin. Viruell-Fuentes, Miranda, and Abdulrahim (2012), referring to the intersectional approach of Crenshaw (1991), call for considering the overall outcomes of the mutually constituted systems that work together to produce inequalities in health. The intersectional approach was originally developed in gender studies as a way of describing how women, migrants, and individuals from lower social classes experience several systems of oppression simultaneously. Accumulating these 
various characteristics results in vulnerability that is deeper than the simple sum of the deficits produced by each social position would suggest. Although migrants experience an advantage in terms of mortality outcomes, translating this approach to health studies remains relevant and promises to provide new explanations of how social factors interact. There is a need to consider the constitutive dimensions of a social position simultaneously - or at least to test whether or not they are independent.

In most previous research, social factors are treated as having the same effect for every individual: they are not evaluated in terms of their social meaning but as controls. This may be the reason why Singh and Siahpush (2002) noticed that the usual social indicators weakly contribute to inequalities among ethnic groups living in the United States. So far, only a few American studies have been interested in the comparison of the socioeconomic gradient in mortality between the migrant population - namely the Hispanic groups - and natives. All these authors conclude that there is a flatter socioeconomic gradient among migrant communities (Goldman et al. 2006; Riosmena and Dennis 2012; Turra and Goldman 2007), which tends to confirm that socioeconomic position does not have the same meaning for all individuals.

Furthermore, migrants are too often seen as an explicit, clearly defined group sharing common practices and cultural habits, which are assumed to be healthier. This homogenization is inappropriate even for (apparently) well-defined groups such as Hispanics in the United States or Mediterranean groups in Europe, because migrants experience different life events and face different circumstances in both their origin and their destination country (Dubowitz, Bates, and Acevedo-Garcia 2010; Hunt, Schneider, and Comer 2004). Each migrant group has its own culture depending on the region of origin, the migration trajectory, and the integration process. Culture is therefore not a unimodal or static variable, but has to be approached through several dimensions (Koehn et al. 2013).

For Acevedo-Garcia et al. (2012), the origin of inequalities in health can therefore be located at the intersection of different social fields, at the crossroads of cultural and structural factors. These factors are composed of gender, socioeconomic, demographic, contextual, historical, and political dimensions. This paper sets out to rethink these interrelations within the social structure. An intersectional perspective implies not only certain theoretical concerns but also a specific methodological approach. As mentioned previously, research in social sciences tends to address the inherent complexity of a social outcome through an additive approach to individual elements. Interaction effects, while obviously enabling us to go beyond a simply cumulative analysis, are used to test precise hypotheses. This paper proposes the use of the inductive method of classification trees to disentangle how social factors interact to modulate mortality risks.

The analysis here is based on a Swiss context, which merits a brief outline. A country of 8 million inhabitants where today more than $23 \%$ of the population are of 
foreign citizenship, Switzerland has one of the largest proportions of migrants in the world. Since World War II, most of the migratory flows have been of workers and their families, who responded to the need of the Swiss economy for a low-skilled workforce and who came first of all from Italy and Spain and later mainly from Portugal, Yugoslavia, and Turkey. In the past two decades the flows and also the intentions of migrants have diversified. More recent immigrants have increasingly entered highskilled occupations, but also continue to meet the demand for labour in the lowest paid jobs. This diversification of origins and polarization of the labour force have made the migrant population much more heterogeneous.

Switzerland is therefore an ideal laboratory in which to highlight how the social determinants of longevity interact to produce better or worse outcomes. This paper does not focus on a unique and defined community but tries to encompass the whole migratory landscape. By classifying migrants according to their region of origin, length of stay, migratory status (first and second generation), and in terms of the integration process (naturalisation), this study attempts to understand the migratory conditions and pathways of a whole and highly diversified population.

\section{Data and methods}

\subsection{Data}

The study uses the data developed by the Swiss National Cohort (SNC), a longitudinal research platform based on the linkage of individual mortality data at the national level (Bopp et al. 2009). Probabilistic record linkage methods were used to assign to each death (1990-2008) a record in the population census (1990 and 2000). This enables the whole population living in Switzerland from the census until death (or emigration or survival) to be followed in a longitudinal perspective. Almost $94 \%$ of the deaths which occurred between $5^{\text {th }}$ December 1990 (the day after the 1990 census) and the end of December 2008 could be linked with the 1990 or 2000 censuses (Spoerri et al. 2010).

The Swiss federal statistical office also registers the foreign population in the central alien register, so that the SNC can take into account emigration occurring among foreigners. Since individual identification numbers in the central alien register were introduced only in the mid-1990s, the SNC could link emigrations with the 2000 census only. The probabilistic linkage between the 2000 census and the central alien register has a lower rate of correspondence. About $87 \%$ of the foreigners recorded in the census could be found in the alien register, mainly because of diverging definitions of the population (including, for example, asylum seekers, seasonal permits, and diplomatic residence authorisations) and the lack of reliable characteristics present in the two 
sources. Therefore, of the 914,939 foreigners aged between 25 and 64 who were counted in the 2000 census, only the 799,287 also registered in the central alien register could be retained. This population, and all Swiss nationals $(5,786,457$ persons) were followed from the $1^{\text {st }}$ of January $2001^{2}$ to the $31^{\text {st }}$ December 2008 . Whereas the exact exposure time is known for foreigners (controlled by emigration), we have to assume that all Swiss nationals who do not die are still in the country at the end of the studied period. As a whole, the population of interest lived 31,097,222 person-years and experienced 77,676 deaths. Table 1 shows a selection of characteristics for this cohort.

Table 1: Number of deaths and person-years for selected characteristics, SNC 2001-2008

\begin{tabular}{llll}
\hline Age & Deaths & Person-years & \% person-years \\
\hline $25-29$ & 1,756 & $3,279,214$ & 10.5 \\
$30-34$ & 2,401 & $3,841,331$ & 12.4 \\
$35-39$ & 3,796 & $4,531,685$ & 14.6 \\
$40-44$ & 5,750 & $4,602,830$ & 14.8 \\
$45-49$ & 8,436 & $4,181,374$ & 13.4 \\
$50-54$ & 12,472 & $3,862,394$ & 12.4 \\
$55-59$ & 18,696 & $3,669,536$ & 11.8 \\
$60-64$ & 24,369 & $3,128,858$ & 10.1 \\
\hline Sex & & \\
\hline Male & 49,677 & $15,490,773$ & 49.8 \\
Female & 27,999 & $15,606,449$ & 50.2 \\
\hline Education level & & \\
\hline Compulsory & 18,001 & $55,46,422$ & 17.8 \\
Upper secondary & 43,268 & $17,409,466$ & 56.0 \\
Tertiary & 14,753 & $7,225,072$ & 23.2 \\
Unknown & 1,654 & 916,262 & 2.9 \\
\hline Nationality & & \\
\hline Swiss citizenship & $67^{\prime} 959$ & 82.3 \\
Foreign citizenship & $9 \mathbf{\prime}^{\prime} 717$ & $55^{\prime} 583^{\prime} 034$ & 17.7 \\
\hline Country of birth & & & \\
\hline Switzerland & 61,219 & $23,321,198$ & 1.2 \\
Abroad & 15,352 & $7,395,775$ & \\
Unknown & 1,105 & 380,250 & \\
\hline
\end{tabular}

${ }^{2}$ The 2000 census occurred on the $5^{\text {th }}$ of December. For convenience reasons, the follow-up began at the beginning of January 2001. 
The analysis only focuses on the population of adult working age. Individuals above 65 years were not taken into account because of the low quality of the data on the socioeconomic status of retired individuals in the 2000 census. Moreover, as Swiss immigration flows started growing after World War II, old immigrants are less numerous and less heterogeneous than the subsequent generations of immigrants.

This initial data frame is a person-years file with more than 30 million lines, which makes even the computation of simple statistics difficult. The data have therefore been aggregated according to each profile (a combination of all categorical variables), summing the number of deaths and person-years in order to arrive at a more reasonable data frame containing around 775,000 lines.

\subsection{Classification trees and modelling strategy}

The analytical strategy followed a two-step procedure. The first part was an exploratory and inductive approach that aims to uncover the main interacting structures. In the second part, classical regression models were used to support the major outcomes and provide inferential results.

To detect interactions within the social structure, an inductive method was used. Classification trees have the advantage of not postulating forms of relations between variables. Although they are not often used in the social sciences, classification trees are a data-driven process developed to class populations - to achieve more homogenous groups - according to a dependent variable (Ritschard 2013). The trees are grown by successive binary splits of the population according to the most discriminant variable. Working in an iterative way until no significant differences are observed in a node, the method creates a hierarchical structure (the trees) in which each node depends on previous splits.

A hypothetical example of attempting to determine how mortality drivers interact illustrates the procedure. After introducing the population of interest, the algorithm will estimate the most discriminant factor; let us say, sex. In the first node, the population will be split according to sex. Then, for each category, the algorithm assesses again the most discriminant variable and splits the sub-populations according to it; for example, having a job or not for men and getting married or not for women. This process continues for workingmen and for all other nodes as long as any differences are observed. The final result is a tree containing successive binary splits of the population.

While the primary purpose of the classification trees is to identify sub-populations within a given population, the method also allows the identification of structures in the data, namely interactions. The most significant explanatory variable for one subgroup may have no effect on another one. Applying classification trees to the study of 
inequalities in longevity reveals a conjunction of factors leading to vulnerability or, in the opposite case, having a protective effect against the risk of death. This methodology is distinct from standard regression models because it estimates not mean effects but specific effects. This kind of exploratory methodology is likely to have wide applicability in the social sciences and to enhance understanding of how social structure drives inequality.

Since the early work of Breiman and colleagues (Breiman et al. 1984), classification and regression trees (CART) have developed, and a wide range of methods exists today (Ritschard 2013). As mortality is mainly driven by the ageing process, early CART methods whose split criteria are based on the Chi square association (Kass 1980) or the change of deviance according to a Poisson distribution (Therneau and Atkinson 1997) are inappropriate, because age will systematically be the most important predictor and the resulting tree would have as many initial splits as age classes. The model-based recursive-partitioning framework (Hothorn, Hornik, and Zeileis 2006; Zeileis, Hothorn, and Hornik 2008) offers a good alternative, since it estimates models allowing for control variables - such as age. In consequence, it is not a black box from which an obscure data-mining algorithm extracts information, but is rather a theory-driven tool (Kopf, Augustin, and Strobl 2013). Built on parametric models such as from the exponential family, these trees distinguish modelling from partitioning variables. The procedure recursively applies the four following steps to a dataset (Zeileis, Hothorn, and Hornik 2008): 1) fit of a parametric model in regard to the set of modelling variables; 2) test of the parameter instability (Zeileis and Hornik 2007) using the partitioning variables; 3 ) if there is an instability, computation of the best partition - for categorical variables it tests all possible partitions for a binary split and split of the data; 4) repetition of the procedure for each daughter node.

In this paper, mortality is approached using a Poisson rate model (Powers and Xie 1999) in which the counts of deaths for each profile follow a Poisson distribution weighted by the person-years. The modelled rate is the expectation of counts $\left(\mu_{i}\right)$ divided by the exposure $\left(t_{i}\right)$. The exposure is fixed to a coefficient of one and is known as an offset. Taking the logs, it gives the following loglinear regression model, with $\beta_{k}$ the $k$ estimated parameters, and $x_{k}$ the independent variables:

$$
\ln \left(\mu_{i}\right)=\sum_{k} \beta_{k} x_{k i}+\ln \left(t_{i}\right)
$$

Due to the over-strong assumption of the Poisson distribution assuming equality between mean and variance a quasi-likelihood estimation was preferred, taking into account the over-dispersion. For these quasipoisson generalized linear models, the variance is multiplied by a parameter $\phi$ proportional to the mean. This statistical frame 
is applied both to the model-based recursive partitioning and the confirmatory analysis which tests afterward whether the interactions effects raised in the tree can be observed in the whole population. All statistical analyses were run in R (R Core Team 2015) and the tree grown with the Party package (Zeileis, Hothorn, and Hornik 2010).

The model-based trees consider two types of variable: partitioning and modelling. Fifteen partitioning variables were used here and are the dependent dimensions structured by the tree. Table 2 lists them and their numerical code for each category. To understand mortality differentials, demographic-, socioeconomic-, contextual-, and migration-related dimensions were considered. Several variables could be expressing the same idea with nuances, but this has no estimation consequences because they are used for splitting a dataset and not modelling it.

The migration dimensions considered here are chosen to explore the diversity inside this notion. The data used come from a census so the explanatory factors stay at the social stratification level; the constitutive dimensions of the migrant experiences in the host countries, i.e., social support and integration, cannot be taken into account in the analysis. The significant diversity among migrants, as discussed in the introduction, is accounted for as far as possible, rejecting the assumption of homogeneity (Dubowitz, Bates, and Acevedo-Garcia 2010; Hunt, Schneider, and Comer 2004). Previous research has approached migration from either an ethnic or an immigration point of view, and has generally tried to integrate assimilation theory into the understanding of health inequalities. This paper also aims to encompass these aspects. Indeed, the tree procedure is able to detect, for each position in the social stratification, which is the most discriminant sub-dimension. Consequently, the partition variables distinguish the origin by nationality; i.e., the country of birth from the immigration process. The process of integration into Switzerland could be approached either through length of stay (years after arrival or age at arrival) or by the acquisition of Swiss nationality. A synthetic binary variable distinguishes between Swiss natives and individuals with at least one characteristic of a foreign origin.

The modelling variables can be interpreted as controls. As mortality is mainly driven by the ageing process the only modelling variable included is age in five-year categories. Moreover, the M-fluctuation test for instability is only applied on the constant (the reference category of the age variable), because we are here interested in the variability around an age-controlled mortality level but not in some slope effects (mortality variations between age groups). As this analysis departs from a hypotheticodeductive framework, the instability tests have p-value adjusted according to a Bonferroni correction. This correction takes into account the multiple tests done and thus the probability of randomly finding a significant association. Because of the size of the data set, a small p-value of 0.000001 was chosen. 
Table 2: Partition variables used in the classification tree analysis

\begin{tabular}{|c|c|}
\hline \multicolumn{2}{|l|}{ DEMOGRAPHIC } \\
\hline Sex $(\operatorname{sex})$ & $1=$ male, $2=$ female \\
\hline Marital status (marital) & $1=$ single, $2=$ married, $3=$ widow, $4=$ divorced \\
\hline Living with a partner (partner) & $1=$ no, $2=$ yes \\
\hline \multicolumn{2}{|l|}{ SOCIOECONOMC } \\
\hline Highest completed education (educ) & $\begin{array}{lll}\text { 1=compulsory, } 2=\text { upper } & \text { secondary, } & \text { 3=tertiary, } \\
4=\text { =unknown } & & \end{array}$ \\
\hline Employment status (employment) & $\begin{array}{l}1=\text { full time, } 2=\text { part time, } 3=\text { =in education, } 4=\text { job-seeking, } \\
5=\text { at home, } 6=\text { pensioner, } 7=\text { other inactive }\end{array}$ \\
\hline Socio-professional category $(S P)$ & $\begin{array}{l}1=\text { top management and independent professions, } \\
2=\text { other self-employed, } 3=\text { =professionals and senior } \\
\text { management, } 4=\text { supervisors/low-level management and } \\
\text { skilled labour, } 5=\text { unskilled employees and workers, } \\
6=\text { other employee, } 7=\text { not in paid employment }\end{array}$ \\
\hline Education of partner (educ.part) & $\begin{array}{l}1=\text { compulsory, } \quad 2=\text { upper secondary, } 3=\text { =tertiary, } \\
4=\text { unknown, } 5=\text { not living with a partner }\end{array}$ \\
\hline \multicolumn{2}{|l|}{ CONTEXT } \\
\hline Language region (region) & 1=German, 2=French, 3=Italian \\
\hline Urbanisation (urban) & $1=$ urban, $2=$ peri-urban, $3=$ single city, $4=$ rural \\
\hline \multicolumn{2}{|l|}{ MIGRATION } \\
\hline Nationality by major group (nat2) & $\begin{array}{l}0=\text { Swiss, } 1=\text { Italian, } 2=\text { Portuguese and Spanish, } 3=\text { Ex- } \\
\text { Yugoslavian, } 4=\text { Turkish, } 5=\text { German, French, or Austrian, } \\
6=\text { other Northern countries, } 7=\text { other Southern countries }\end{array}$ \\
\hline Country of birth (natbirth) & $1=$ Switzerland, $2=$ =abroad, $3=$ unknown \\
\hline Naturalisation (natu) & $\begin{array}{l}1=\text { Swiss citizenship from birth, } 2=\text { naturalised Swiss, } \\
3=\text { foreigner }\end{array}$ \\
\hline Foreign origin (foreign.origin) & $\begin{array}{l}1=\text { Swiss citizen born in Switzerland (and not } \\
\text { naturalized), } 2=\text { of foreign origin }\end{array}$ \\
\hline Year of arrival $^{*}$ (year.arrival) & $\begin{array}{l}\text { 1=1995-2000, 2=1990-1994, 3=1973-1989, 4=before } \\
\text { 1973, 5=born in Switzerland, 6=Swiss citizenship }\end{array}$ \\
\hline Age at arrival* (age.arrival) & $\begin{array}{l}1=\text { born in Switzerland, } 2=\text { before } 12 \text { years, } 3=12-17 \\
\text { years, } 4=18-44 \text { years, } 5=45-59 \text { years, } 6=60 \text { and more, } \\
7=\text { Swiss citizenship }\end{array}$ \\
\hline
\end{tabular}

Note: * Variable extracted from the central aliens register and available only for foreigners.

The conditional form of the trees is an important limit. In the test of instability the differences between one partition variable and another could be very slight, and the choice of the most discriminating variable has a major influence on all subsequent nodes and the form of the tree. Classification trees stay at an exploratory level, with specific effects arising from conditional distribution. The procedure was therefore repeated with several sub-samples of the data in order to arrive at a more definitive idea of the effects which emerge. 


\section{Results}

\subsection{The explanatory analysis}

A classification tree, developed as discussed in the previous section, is presented in Figure 1 . The nodes are coloured according to the mortality rate estimated on an agestandardized population: the darker the shade of red, the higher the mortality rate; the darker the shade of blue, the lower the mortality rate. This representation permits a good visualisation of how mortality is structured, with some niches of low risk and others of high vulnerability. Moreover, in each node the reader will find an estimation of the age-standardized mortality rate per thousand and, in the branches, the numerical code for the split categories (with reference to Table 2). Finally, each final leaf indicates the number of deaths, and the person-years lived by foreigners and Swiss citizens. This section presents only the main results, rather than enumerating each of the numerous splits. Interested readers can follow these in Figure 1. The interpretations are expanded and discussed in the conclusion, after the presentation of the confirmatory model.

The standardized mortality rate at the population level is evaluated at $2.5 \%$. Interestingly, the first split of the tree does not refer to sex but to employment status, dividing the population between those individuals receiving a pension (rate of 10.7\%o) and others (rate of 2.3\%). These 'renters' are not pensioners, because the analysis focuses on those of working age, but disabled persons, who are of course a small subgroup representing $2 \%$ of the person-years. Their vulnerability is striking, as their mortality rate is more than 4 times higher than for the rest of the population. Among this group, origin appears as the most important dimension. Individuals with a foreign background (rate of 6.7\%o) have a lower mortality than Swiss natives (rate of 13.6\%). For the Swiss, sex is the most discriminant variable - men tend to have a higher risk rate $(15.3 \%$ ) than women $(11.2 \%)$ - while for those of foreign origin, married people and widowers have a much lower rate (4.9\%) than single and divorced persons $(10.9 \%)$. Sex seems to have less influence for pensioners and for those with a foreign background, as it does not appear as a splitting variable. 
Figure 1: Model-based classification tree of mortality (age standardized mortality rate per thousand)

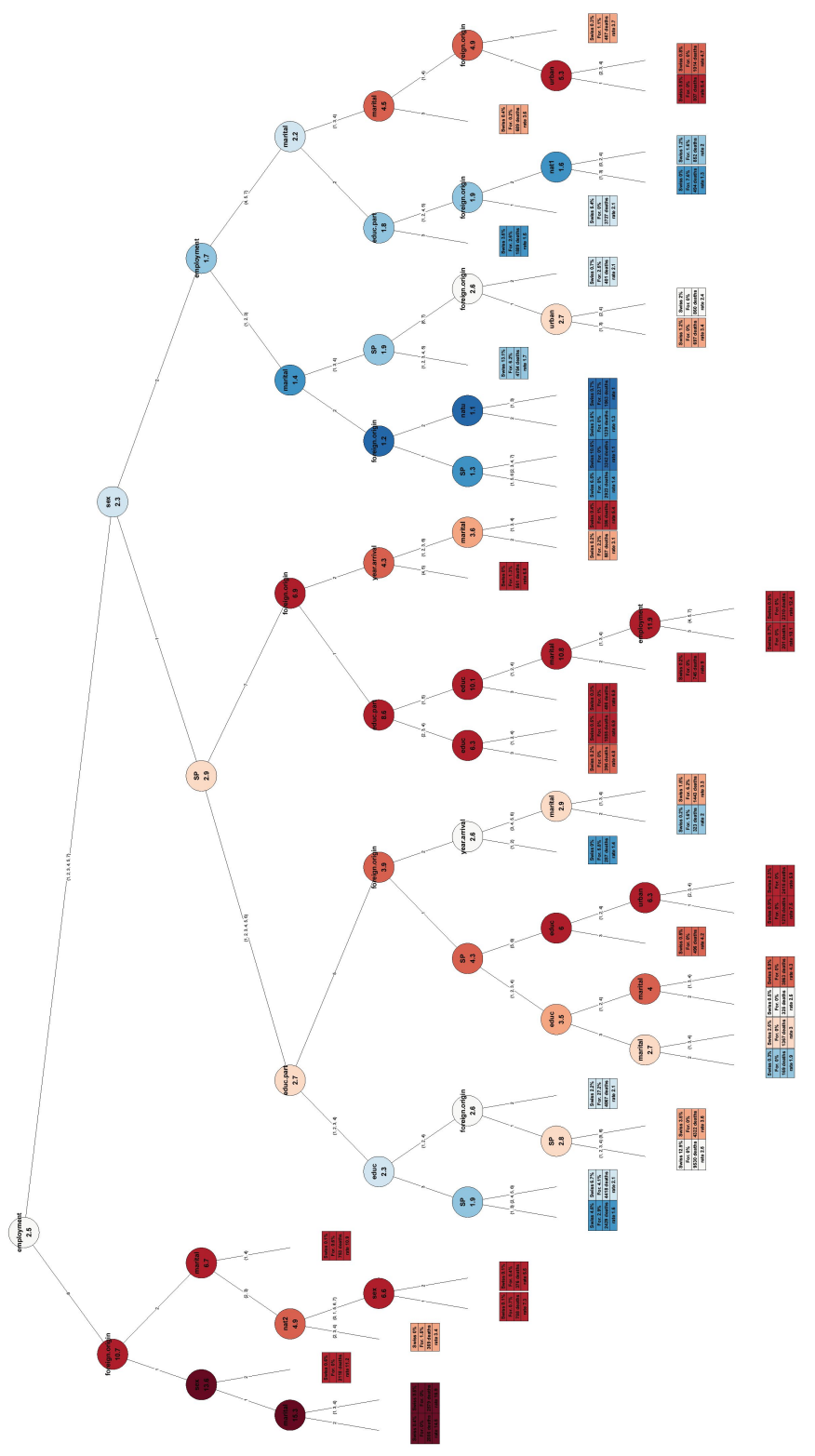


Among the rest of the population, however, the most discriminant variable is sex. For women (on the right hand side of figure 1), the first split divides women who are active in the labour market or studying (rate 1.4\%o) from those who are not (rate of $2.2 \%$ ). Then, for both situations, marital status emerges as the next splitting variable: as is well known, being married has a protective impact in terms of mortality. However, an accumulation of aggravating factors appears: women who are both inactive and unmarried have a substantial rate of mortality $(4.5 \%$ ), whereas the risk is much lower for the active and unmarried (1.9\%), or the inactive but married $(1.8 \%)$, and for those who are both active and married $(1.2 \%)$. Marriage could be interpreted as a compensation factor for being excluded from the labour market ${ }^{3}$. As we anticipated in our initial discussion introducing the intersectionality approach, individuals cumulating the two disadvantages have an exacerbated risk of death that is not a simple addition of the two hazards.

Among the subsequent nodes of the other women, foreign origin finally appears several times and is always to the relative disadvantage of Swiss natives. Interestingly enough, the differentiating factor for inactive but married women is the level of education of their partner rather than their own level. To have a partner with a tertiary degree has a positive effect on inactive women (rate of $1.5 \%$ versus $1.9 \%$ for the others), indicating the powerful protective effect of marriage through the economic contribution of the 'male breadwinner', which is still effective today in $21^{\text {st }}$ century Switzerland.

The part of the tree referring to men is firstly split by activity in the labour market ${ }^{4}$. Active men present a much lower mortality rate $(2.7 \%$ ) than those who do not work $(6.9 \%)$. Among the latter, foreign origin is the most discriminant variable, meaning that inactive Swiss natives are more vulnerable (rate of $8.6 \%$ ) than foreigners in the same situation (rate of $4.3 \%$ ). Individuals of foreign origin are then split by the length of their stay. On the one hand, the oldest migrants (those who arrived before 1973) and foreigners born in Switzerland have a high rate of 6.9\%o, while on the other hand all other foreign immigrants and Swiss with a migratory background (i.e., naturalized Swiss or Swiss born abroad) face lower risks (3.6\%). In the latter group, marriage has a significant protective effect (rate of 3.1\% versus 5.4\% for the unmarried). For other inactive persons with a foreign background, there are no further splits. Among Swiss natives who are inactive, the partner and her level of education is the most important dimension. Not living with a partner or living with a partner with only a compulsory level of education increases the mortality rate $(10.1 \%$ ) in

\footnotetext{
${ }^{3}$ This relation can also be interpreted in the opposite way, since there is no causality in the tree: being active can compensate the risk of not being married.

${ }^{4}$ There is a nuance in defining activity. For women, activity was defined by employment status (which includes students). The split among men is done using the socio-professional category. Consequently, for men, students are not included among the active population.
} 
comparison to living with a partner having a higher degree (rate of $6.3 \%$ ). Then, in both subsequent nodes, a tertiary level of education reduces the mortality risks.

Men active in the labour market are differentiated according to their partner. Those who cohabit have a lower risk of dying (rate of 2.3\%) than those who do not (rate of $3.9 \%$ ). Workingmen living alone follow different logics according to their origin. Those of foreign origin are separated by the length of stay: the most recent flows immigrants who arrived within the 10 years before the beginning of the observation have a very low risk of death (rate of 1.4\%o) in comparison to the others (rate of 2.9\%o). The latter are furthermore split according to their marital status (marriage implying a lower risk of death). Swiss workingmen not living with a partner are mostly differentiated by socioeconomic position. Firstly, the socio-professional category marks the difference - unskilled workers and those in the "other" category are more vulnerable (rate of 6\%o) than all the others (rate of 3.5\%). Secondly, the level of education appears to be determinant for both groups - a tertiary degree protecting against death.

Among active men sharing their life with a partner, the level of education is again the most discriminant variable. Individuals with a tertiary level of education (rate of $1.9 \%$ ) are then split by socio-professional category; as expected, the top managers, independent professionals, and senior managers have a lower rate $(1.6 \%)$ than all the others $(2.1 \%$ ). Among those with lower levels of education (rate of 2.6\%o) the first discriminant variable is foreign origin. Again, foreign individuals have a lower risk of death (rate of $2.1 \%$ ) than Swiss natives (rate of $2.8 \%$ ).

The description of the tree dynamics is long, and as specific effects are described it may be difficult for the reader to grasp the whole idea. But this analysis enables an understanding of how mortality is structured by demographic and socioeconomic factors. Through the construction process, conditional effects emerge and highlight the most discriminant factor for a sub-population. As the algorithm splits the population into two groups, the tree always displays dichotomist structures, although in fact the diversity inside each node may be important and the risks may follow, for example, linear or quadratic forms. Furthermore, since age was selected as a modelling variable it was not possible to compare the intersection between age and social stratification. The procedure was therefore repeated for sub-samples of different age groups ${ }^{5}$. In general, the results confirm the same pattern. The differential impact of the first split - those receiving a pension versus those who do not - is even more pronounced for the younger age groups who are, by comparison, more vulnerable to disability.

\footnotetext{
${ }^{5}$ A tree for the 65-79-year-old population has also been grown, but, as presented earlier, the SES status for the retired is not of good quality, and the migrant population is much more homogeneous. The resulting tree reveals other dynamics and mainly factors like living alone, level of education, and partner level of education (only for women living with a partner).
} 
For the reasons suggested above, classification and regression trees remain at an exploratory level, and there is a need to build statistical models that are able to infer the preliminary pattern outlined here. The next subsection presents a confirmatory analysis of the most important results related to migratory background.

\subsection{The confirmatory analysis}

Here, the aim is to validate the main outlines of the classification tree with placed interactions in regression models, in order to move from the explanatory level to a confirmatory level. The classification tree was able to map the structure of the mortality risks within the social stratification, but not to propose an inferential model. It provided an overview of social dynamics; for example, as these affect the vulnerability of pensioners and those not engaged in the labour market. The explanatory findings also show diverging dynamics for men and women. Among men, socioeconomic position appears to be the main driver of inequality in longevity. For women, it is already known that mortality differentials are less pronounced. The tree pointed to only slight differences across the socioeconomic gradient or according to the level of education. However, we were able to observe an accumulation of risk factors for those who do not work and are not married.

Foreign origin, which is central to this research, emerged as one of the most important variables for men, and appears to act as compensation or protection both in the high risk profiles (being inactive or a pensioner) and in low social positions (low level of education or socio-professional category). The subsequent nodes following the split between foreign and native origin tend to concern the educational gradient for Swiss natives but not for individuals of foreign origin. For the latter, the year of arrival, expressing both integration and selection effects, seems to be determinant.

These results are of major interest in the research frame of this article because they demonstrate the shaping role of social stratification according to migratory background. To test for confirmation, a first quasipoisson generalized model of death rates was constructed including the most important variables (age, marital status, living with a partner and his/her level of education, ego level of education, socio-professional category, receiving a pension ${ }^{6}$, and migratory background) but no interactions. The variable 'migratory background' was newly created to differentiate individuals by country of birth, citizenship, and length of stay ${ }^{7}$. Separate regressions were run for men

\footnotetext{
${ }^{6}$ Pensioners are a sub-group of inactive persons within the socio-professional category. Therefore both coefficients have to be taken into account.

${ }^{7}$ The variable migratory background has the seven following categories: 1) Swiss from birth, 2) foreigner arrived [1995; 2000], 3) foreigner arrived [1990; 1994], 4) foreigner arrived [1973; 1989], 5) foreigner arrived
} 
and women. In a second model, an interaction was added between migratory background and inactivity (including individuals receiving a pension). This model also tested the social gradient through the level of education for individuals of foreign origin. A third and final model took into account the different dimensions of the migratory background (country of birth, citizenship, and year of arrival) in interaction with activity in the labour market.

The results are presented in Tables 3 and 4 for men and women respectively. The first model shows what we usually see in research on migrants' mortality paradox, with significant effects of the socioeconomic and demographic variables and each dimension modelled independently. It also demonstrates the differential mortality risk between migrants from Southern Europe and Northern countries, the first having a lower mortality. As observed in the tree, the most recent immigrants, and also older migrants and the naturalized Swiss - in a word, everyone with a migratory background - tend to have a lower risk of mortality than those who are Swiss from birth. The only exception concerns naturalised Swiss women. Although until 1992 women with a foreign nationality who married a Swiss partner automatically acquired Swiss citizenship, the Swiss naturalisation process is very selective according to socioeconomic and integration skills (Fibbi, Lerch, and Wanner 2007). A recent study has shown that naturalised women married to a Swiss partner have higher mortality risks than other naturalised individuals because of their lower selection (Zufferey 2014). Nonetheless, the mortality advantage is not located among immigrants only but has a wide scope, encompassing almost all individuals with a foreign background. A gradient according to the length of stay introduces differentials among foreigners. Those of foreign origin but born in Switzerland still have a relative advantage compared to Swiss natives. Swiss naturalised men have an advantage situated at the bottom of the gradient that is not marginal. In regard to the intensity of the coefficients, the reader should note the deep vulnerability affecting individuals who are not part of the labour market and the even more frail position of those receiving a pension.

The second model includes interactions, and goes a step further in considering the position of individuals of foreign origin within the social stratification. For men, this firstly confirms the greater advantage among the highest risk profiles, namely individuals who are not active in the labour market ${ }^{8}$. The model also highlights the flatter social gradient among people of foreign origin, with only slight differences according to the level of education. Among women there is no significant advantage for the inactive of foreign origin, but there is a compensation effect of marriage. Being

before 1973, 6) Second-generation, 7) Swiss with foreign origin. The modality 'Swiss with foreign origin' encompasses the naturalized Swiss and the rare Swiss citizens born abroad.

${ }^{8}$ Individuals receiving a pension are inactive and are therefore modelled in the same way as other inactive persons. A model was also tested that includes separated coefficients for the two groups (not shown). This solution was not retained because the foreign advantage was the same in both situations. 
married reduces the negative impact of inactivity (Falter 2009). Again, as seen among men, we can observe a flatter gradient for the level of education among those of foreign origin.

The third model adds an interaction between inactivity and the foreign-background subgroups. Again, for women, this interaction has no significant effect. Among men, an interesting pattern is observed. Foreign immigrants, in comparison with the Swiss from birth, have reduced mortality even when they are inactive, but most of the time this relation is not significant because of the small size of this population and the many parameters estimated. Swiss of foreign origin are also significantly less affected by inactivity; however, we can observe the opposite relationship for the second generation. Although the 'migrant advantage' needs to be defined very broadly (and as we have seen does not apply uniquely to recent migrants), the findings show that the second generation enjoys no greater protection from mortality risk if they are inactive. Secondgeneration immigrants lose a major part of their advantage when inactive, whereas the protection increases for the other immigrants in the second generation. This is probably due to both integration and selection effects.

Figure 2 gives a synthetic representation of these results for men and women, with a prediction of the mortality rate for a selection of independent variables according to Model 3. It shows the estimated mortality rate for 5 groups of foreign origin ${ }^{9}$ according to different characteristics for socio-economic category, marital status, and level of education; all the other parameters are fixed ${ }^{10}$. The figure shows the high relative and absolute advantage for immigrants in the most vulnerable profiles, namely among persons who do not play a part in the labour force. It also highlights, once again, the flatter gradient according to the level of education among individuals with a foreign background. Finally, Figure 2 illustrates the differentials among individuals of foreign origin. It appears that more recent migration flows have a lower mortality rate than older flows in each profile. Second generations shift in their relative position: those with risky profiles are closer to the position of Swiss natives but all the others are closer to that of the most recent migrants.

\footnotetext{
${ }^{9}$ Here the foreign nationalities are considered all together (mean effect).

${ }^{10} \mathrm{Age}$ is fixed at 45 , the partner has a compulsory level of education, and none of the profiles is receiving a pension.
} 
Table 3: $\quad$ Estimates from a quasipoisson generalized linear model of mortality (controlled for age, marital status, living with a partner, and partner level of education), men 25-64 years

\begin{tabular}{|c|c|c|c|c|c|c|}
\hline & Model 1 & & Model 2 & & lodel 3 & \\
\hline & coef. & sig. & coef. & sig. & coef. & sig. \\
\hline \multicolumn{7}{|l|}{ Education level } \\
\hline Compulsory & ref & & ref & & ref & \\
\hline Upper secondary & -0.08 & $* *$ & -0.12 & $* * *$ & -0.12 & $\star \star \star *$ \\
\hline Upper secondary $\mathrm{x}$ foreign origin & & & 0.17 & ** & 0.17 & ** \\
\hline Tertiary & -0.34 & $* * *$ & -0.39 & $* * *$ & -0.39 & *** \\
\hline Tertiary $\mathrm{x}$ foreign origin & & & 0.19 & * & 0.19 & * \\
\hline Unknown & 0.00 & & -0.06 & & -0.06 & \\
\hline Unknown $\mathrm{x}$ foreign origin & & & 0.18 & & 0.18 & \\
\hline \multicolumn{7}{|l|}{ Social position } \\
\hline Top/indep. Prof. & ref & & ref & & ref & \\
\hline Other self-employed & 0.20 & ** & 0.20 & ** & 0.20 & ** \\
\hline Professional and senior & -0.06 & & -0.05 & & -0.05 & \\
\hline Skilled labour & 0.15 & * & 0.15 & * & 0.15 & * \\
\hline Unskilled labour & 0.36 & $* * *$ & 0.35 & 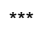 & 0.36 & *** \\
\hline Other employed & 0.46 & *** & 0.46 & 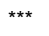 & 0.46 & *** \\
\hline Inactive & 1.00 & 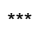 & 1.04 & 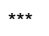 & 1.04 & *** \\
\hline Pensioner & 0.39 & $* * *$ & 0.39 & *** & 0.39 & *** \\
\hline Inactive $\mathrm{x}$ married & & & -0.03 & & -0.03 & \\
\hline Inactive $\mathrm{x}$ foreign origin & & & -0.12 & * & & \\
\hline Inactive $\mathrm{x}$ foreigner arrived $[1995 ; 2000]$ & & & & & -0.20 & \\
\hline Inactive $\mathrm{x}$ foreigner arrived $[1990 ; 1994]$ & & & & & -0.29 & \\
\hline Inactive $\mathrm{x}$ foreigner arrived $[1973 ; 1989]$ & & & & & -0.14 & \\
\hline Inactive $\mathrm{x}$ foreigner arrived before 1973 & & & & & -0.06 & \\
\hline Inactive $\mathrm{x}$ second generation & & & & & 0.41 & * \\
\hline Inactive $\mathrm{x}$ Swiss with foreign origin & & & & & -0.21 & * \\
\hline \multicolumn{7}{|l|}{ Migratory background } \\
\hline Swiss from birth & ref & & ref & & ref & \\
\hline Foreigner arrived $[1995 ; 2000]$ & -0.85 & 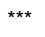 & -0.92 & 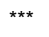 & -0.90 & *** \\
\hline Foreigner arrived [1990; 1994] & -0.72 & $* * *$ & -0.79 & $\star \star * *$ & -0.76 & *** \\
\hline Foreigner arrived $[1973 ; 1989]$ & -0.56 & $* * *$ & -0.62 & $* \star *$ & -0.61 & $\star \star \star *$ \\
\hline Foreigner arrived before 1973 & -0.38 & $* * *$ & -0.43 & $\star \star * *$ & -0.46 & *** \\
\hline Foreigner born in Switzerland & -0.41 & $* \star *$ & -0.49 & $\star \star \star *$ & -0.65 & 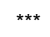 \\
\hline Swiss with foreign origin & -0.27 & $* * *$ & -0.38 & $\star * \star$ & -0.36 & $\star \star \star *$ \\
\hline \multicolumn{7}{|l|}{ Nationality (for foreigners) } \\
\hline Italian & ref & & ref & & ref & \\
\hline Portuguese or Spanish & -0.16 & . & -0.15 & . & -0.16 & . \\
\hline Ex-Yugoslavian & -0.16 & . & -0.15 & . & -0.15 & . \\
\hline Turkish & -0.20 & & -0.17 & & -0.17 & \\
\hline German, French, or Austrian & 0.42 & 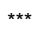 & 0.36 & $\star \star \star *$ & 0.35 & $* \star *$ \\
\hline Other Southern countries & 0.06 & & 0.05 & & 0.05 & \\
\hline
\end{tabular}

Sig. codes: $p<0.001^{\prime * * * \prime}, p<0.01^{\prime * * \prime}, p<0.05^{\prime * \prime}, p<0.1^{\prime \prime}$ 
Zufferey: The migrant mortality advantage at the intersections of social stratification in Switzerland

Table 4: $\quad$ Estimates from a quasipoisson generalized linear model of mortality (controlled for age, marital status, living with a partner, and partner level of education), women 25-64 years

\begin{tabular}{|c|c|c|c|c|c|c|}
\hline & Model 1 & & Model 2 & & Model 3 & \\
\hline & coef. & sig. & coef. & sig. & coef. & sig. \\
\hline \multicolumn{7}{|l|}{ Education level } \\
\hline Compulsory & ref & & ref & & ref & \\
\hline Upper secondary & -0.13 & $* * *$ & -0.15 & $* \star *$ & -0.15 & *** \\
\hline Uppper secondary $\mathrm{x}$ foreign origin & & & 0.15 & * & 0.15 & * \\
\hline Tertiary & -0.21 & *** & -0.22 & $* * *$ & -0.22 & *** \\
\hline Tertiary $\mathrm{x}$ foreign origin & & & 0.05 & & 0.05 & \\
\hline Unknown & 0.14 & & 0.21 & . & 0.21 & . \\
\hline Unknown $\mathrm{x}$ foreign origin & & & -0.20 & & -0.20 & \\
\hline \multicolumn{7}{|l|}{ Social position } \\
\hline Top/indep. Prof. & ref & & ref & & ref & \\
\hline Other self-employed & 0.10 & & 0.10 & & 0.10 & \\
\hline Professional and senior & -0.11 & & -0.11 & & -0.11 & \\
\hline Skilled labour & -0.04 & & -0.04 & & -0.03 & \\
\hline Unskilled labour & 0.05 & & 0.04 & & 0.04 & \\
\hline Other employed & 0.26 & ${ }^{\circ}$ & 0.25 & . & 0.25 & . \\
\hline Inactive & 0.60 & 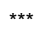 & 0.81 & $\star * \star *$ & 0.81 & *** \\
\hline Pensioner & 0.80 & $\star \star \star *$ & 0.73 & *** & 0.73 & *** \\
\hline Inactive $\mathrm{x}$ married & & & -0.29 & $* \star *$ & -0.29 & *** \\
\hline Inactive $\mathrm{x}$ foreign origin & & & -0.07 & & & \\
\hline Inactive $x$ foreigner arrived $[1995 ; 2000]$ & & & & & -0.19 & \\
\hline Inactive $x$ foreigner arrived [1990; 1994] & & & & & -0.04 & \\
\hline Inactive $x$ foreigner arrived $[1973 ; 1989]$ & & & & & -0.02 & \\
\hline Inactive $\mathrm{x}$ foreigner arrived before 1973 & & & & & -0.06 & \\
\hline Inactive $\mathrm{x}$ second generation & & & & & 0.31 & \\
\hline Inactive $\mathrm{x}$ Swiss with foreign origin & & & & & -0.10 & \\
\hline \multicolumn{7}{|l|}{ Migratory background } \\
\hline Swiss from birth & ref & & ref & & ref & \\
\hline Foreigner arrived $[1995 ; 2000]$ & -0.79 & *** & -0.76 & *** & -0.69 & *** \\
\hline Foreigner arrived [1990; 1994] & -0.62 & $* * *$ & -0.60 & $* * *$ & -0.61 & $* * *$ \\
\hline Foreigner arrived $[1973 ; 1989]$ & -0.55 & $\star \star \star *$ & -0.55 & $* \star *$ & -0.57 & *** \\
\hline Foreigner arrived before 1973 & -0.38 & $* \star * *$ & -0.38 & *** & -0.38 & ** \\
\hline Foreigner born in Switzerland & -0.32 & . & -0.35 & * & -0.51 & * \\
\hline Swiss with foreign origin & -0.06 & & -0.11 & & -0.10 & \\
\hline \multicolumn{7}{|l|}{ Nationality (for foreigners) } \\
\hline Italian & ref & & ref & & ref & \\
\hline Portuguese or Spanish & -0.22 & & -0.23 & & -0.23 & \\
\hline Ex-Yugoslavian & -0.04 & & -0.03 & & -0.04 & \\
\hline Turkish & -0.25 & & -0.22 & & -0.23 & \\
\hline German, French, or Austrian & 0.34 & $* *$ & 0.29 & * & 0.28 & * \\
\hline Other Southern countries & 0.29 & . & 0.24 & & 0.24 & \\
\hline
\end{tabular}

Sig. codes: $p<0.001^{* * * \prime}, p<0.01^{* * * 1}, p<0.05^{\prime * \prime}, p<0.1^{\prime \prime}$. 
Figure 2: $\quad$ Predicted mortality rate for selected profiles, results from Model 3, men and women

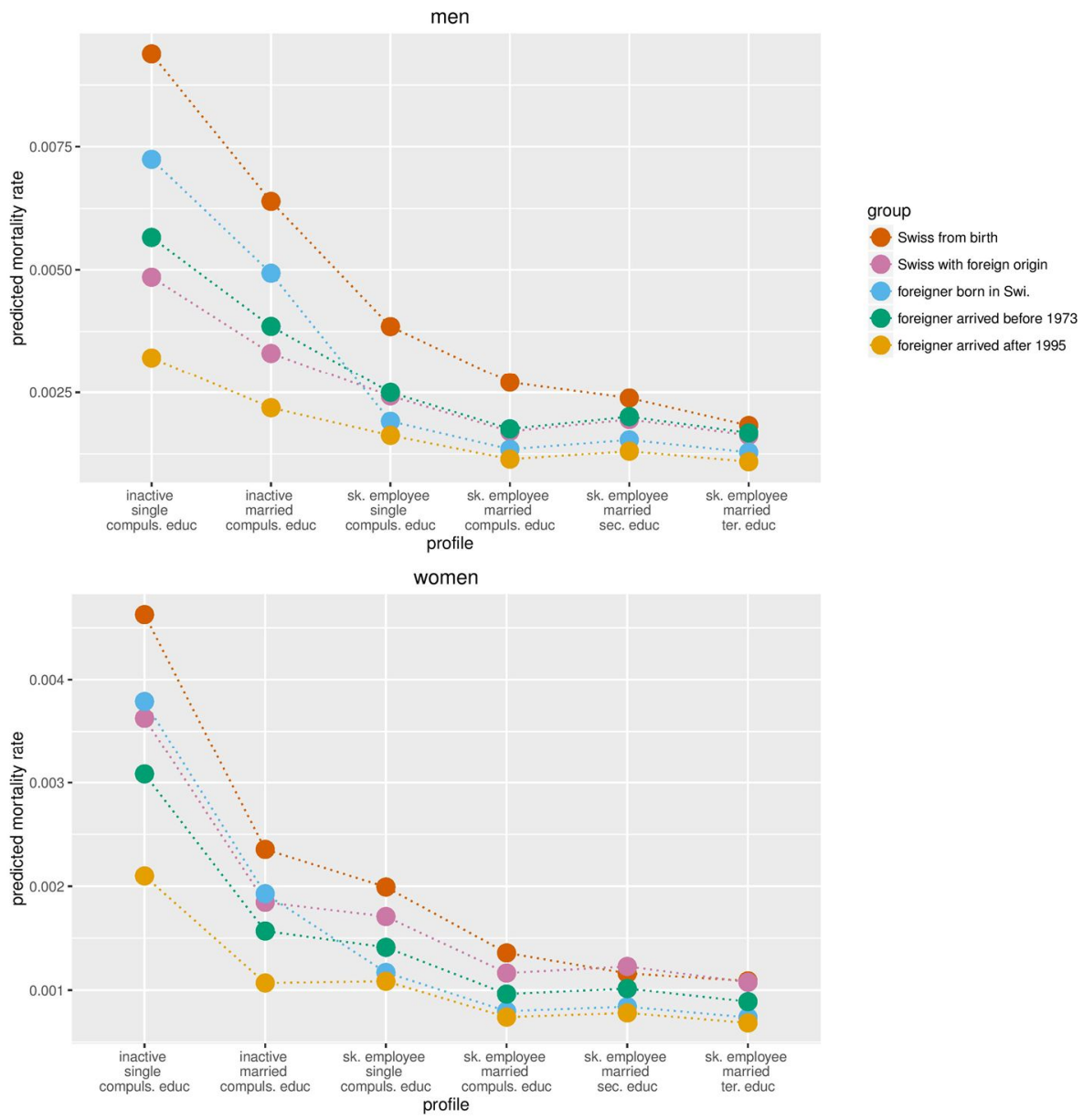

\section{Discussion}

This paper presents a test of an innovative methodology to detect how social strata interact to create inequalities in longevity, with a focus on the differentials between migrants and natives. In the first part, a classification tree was developed which gave a 
useful map of all the social dynamics at stake. In a second step, and in regard to the migrant mortality advantage, a confirmatory analysis added three significant results to the understanding of the factors shaping the migrant mortality paradox. First, the findings showed that the mortality advantage is not only located among foreigners but encompasses a wide population with a foreign background. Secondly, it has been demonstrated that the migrant mortality advantage is stronger in the most vulnerable profiles. Thirdly, and as a consequence, the socioeconomic gradient - the shape of the inequalities according to social position - is flatter among individuals with a foreign background.

Tracking the migrant mortality paradox among all individuals with a foreign background indicates that there is a need to widen the phenomenon's definition. Most research in Europe has approached migration either through citizenship or through country of birth. The findings reported here demonstrate that these two spheres in the definition of migration do indeed overlap, but, more importantly, that each has its own rationale. Moreover, it confirms that among the three generally recognised factors - inselection, out-selection, and negative acculturation process - there is more than one explanation of the advantage. Being born in the country, second-generation immigrants are, by definition, excluded from the selection process, but still have lower mortality risks. Swiss people of foreign origin are either naturalised or are Swiss citizens born abroad and should, at least formally, have acquired Swiss cultural specificities. As discussed above, the Swiss naturalisation process is very selective and requires high acculturation and integration skills. Therefore, the explanation of the mortality paradox is not only a question of selection or the acculturation process, but needs to mobilize several factors.

The accentuation of the migrant mortality differentials in the most vulnerable profiles is the most important contribution of the inductive methodology used here. Scholars in mortality research and more generally in the social sciences tend to consider that an accumulation of risk factors acts additively, whereas the intersections of the social position are much more complex. The generalization of the use of regression models produces a simplification of the social realities that is appropriate, but which may also lead to misspecification in the understanding of our social world. Figure 2 gives a more faithful illustration, in which the relative and, even more, the absolute differentials among the categories of foreigner are significant for the more vulnerable profiles.

In particular, these differences highlight the selective processes of migration. As has been shown in the United States, selection mostly affects dimensions linked with the working population (Bostean 2013) but also protects against death when an individual falls into inactivity. Since the end of World War II, Switzerland has relied on migrant workers to fill low-skilled jobs. The selection process linked to emigration 
leads to greater homogeneity among those who undertake migration. So, for example, migration is less likely to concern individuals with a disability, or those affected by a rare, chronic, or genetic disease. Return migration acts as a second filter against immigrants getting into vulnerable situations. Some would prefer to stay in the host country to benefit from better health services, but for others, who lack job opportunities and have economic difficulties and/or possibly no support from relatives, return migration may appear as the better solution for immigrants in distress. Both in- and outselections thus act to produce less vulnerability, and a homogenization of the healthiest, among the most vulnerable immigrants.

The role of selection in vulnerable profiles can also be analysed through the lens of the second generation. Because these individuals cannot benefit from selection, those who are inactive have a high mortality rate (very close to that of Swiss natives). As discussed earlier, this differential shifts among second generation immigrants active in the labour market, who have one of the lowest mortality rates (Figure 2). Therefore, the explanation must reside elsewhere than in selection. In a recent paper, Mackenbach (2012) has argued that psychosocial dimensions may interplay to explain the persistence of health inequalities in modern welfare states. For second-generation immigrants, such factors - which are not strictly cultural but are linked with a migration background, for example, more hope or desire to succeed as suggested by Anson (2004) or Telles and Ortiz (2008) - could be part of the explanation. Consistent with this idea, Bolzman, Fibbi, and Vial (2003) have demonstrated that second-generation Italian and Spanish immigrants in Switzerland experience more success at school and in the labour market than the children of Swiss manual workers, apparently because of a family culture of effort in migrants families that encourages the success of their young members.

The smaller socioeconomic gradient for persons with a foreign background is a consequence of the concentration of the mortality advantage among the lowest social positions. The slope of the social gradient is steeper for Swiss natives because the differential is bigger among the more vulnerable, while this differential is marginal in the highest social positions. This result is important because the non-inclusion of the flatter mortality gradient among individuals with a foreign background tends to underestimate the strength of the differentials. Two American studies focusing on the Hispanic communities have already highlighted this situation (Riosmena and Dennis 2012; Turra and Goldman 2007), and both emphasise the role of selection processes in creating a positive homogenization among those with lower status. However, Riosmena and Dennis (2012) also add three explanations that are specific to the Latino paradox in the United States, namely the importation of the gradient from the origin countries, negative acculturation that tends to be concentrated at the highest socioeconomic levels, and some data artefacts. These processes do not fit with the context and the immigration 
flows that have characterized Switzerland. Again, besides the selections of the frailer, the flatter gradient among individuals with a foreign background may be related to psychosocial factors associated with migration, a 'culture of migration', such as hope and will to succeed, which may have more positive effects among individuals at the lowest levels of the social scale.

Previous research, for example, Schumacher and Vilpert (2011), has shown that social inequalities in mortality are structured by gender. This paper has also highlighted the fact that factors shaping mortality differ by sex. Among men, foreign background has a major influence in flattening the mortality gradient. By contrast, among women, foreign origin does not appear to be discriminant, for two reasons. First, the selection processes in immigration are typically stronger for men (Khlat and Darmon 2003). Second, the socioeconomic gradient is flatter among women so the influence of other factors becomes marginal.

The approach proposed in this paper has some important results but also some limitations. First, because of the poor data quality regarding the socioeconomic position of the population aged 65 and more, and because of the characteristics of older migrants in Switzerland, the elderly have been excluded from the analysis. Further research should test whether the patterns highlighted here also apply among the $65+$ population. Secondly, the conditional structure of the trees means it stays at an explanatory level, since each node depends on the previous ones. Therefore, this kind of analysis could bring out patterns that are too close to the data (the populations and the time frame analysed).

As a concluding remark, inductive methods such as the classification tree developed here are very fruitful tools. The method enables mainstream assumptions to be disentangled, and highlights how social factors interact with each other. In the social sciences there is a need to widen discussion of the dynamics behind inequalities, and to find ways to analyse the intersection of social stratifications. The material presented in this paper is an illustration that the effects do not always act additively but interact with each other, and need to be approached and measured in that way.

\section{Acknowledgments}

The author warmly thanks Michel Oris and Manuela Schicka for their careful review of this article. Constructive feedback was also provided by two anonymous reviewers. This paper is the result of research executed within the frameworks of the National Competence Centre in Research LIVES and the National Competence Centre in Research on the move. The author also thanks the Swiss Federal Statistical Office for providing mortality and census data and for the support which made the Swiss National 
Cohort and this study possible. This work was supported by the Swiss National Science Foundation (grant nos. 3347CO-108806, 33CS30_134273 and 33CS30_148415). The members of the Swiss National Cohort Study Group are Matthias Egger (Chairman of the Executive Board), Adrian Spoerri and Marcel Zwahlen (all Bern), Milo Puhan (Chairman of the Scientific Board), Matthias Bopp (both Zurich), Nino Künzli (Basel), Fred Paccaud (Lausanne) and Michel Oris (Geneva). Finally, many thanks to Duncan Fulton for the elegant English editing he has provided. 


\section{References}

Abraido-Lanza, A., Dohrenwend, B., Ng-Mak, D., and Turner, J. (1999). The Latino mortality paradox: a test of the salmon bias and healthy migrant hypotheses. American Journal of Public Health 89(10): 1543-1548. doi:10.2105/AJPH.89.10.1543.

Abraido-Lanza, A.F., Chao, M.T., and Flórez, K.R. (2005). Do healthy behaviors decline with greater acculturation? Implications for the Latino mortality paradox. Social Science \& Medicine 61(6): 1243-1255. doi:10.1016/j.socscimed.2005.01.016.

Acevedo-Garcia, D., Sanchez-Vaznaugh, E.V., Viruell-Fuentes, E.A., and Almeida, J. (2012). Integrating social epidemiology into immigrant health research: A crossnational framework. Social Science \& Medicine 75(12): 2060-2068. doi:10.1016/j.socscimed.2012.04.040.

Anson, J. (2004). The migrant mortality advantage: a 70 month follow-up of the Brussels population. European Journal of Population 20(3): 191-218. doi:10.1007/s10680-004-0883-1.

Bolzman, C., Fibbi, R., and Vial, M. (2003). Secondas-Secondos. Le processus d'intégration des jeunes adultes issus de la migration espagnole et italienne en Suisse. Zurich: Seismo.

Bopp, M., Spoerri, A., Zwahlen, M., Gutzwiller, F., Paccaud, F., Braun-Fahrlaender, C., Rougemont, A., and Egger, M. (2009). Cohort Profile: The Swiss National Cohort - a longitudinal study of 6.8 million people. International Journal of Epidemiology 38(2): 379-384. doi:10.1093/ije/dyn042.

Bostean, G. (2013). Does selective migration explain the Hispanic Paradox? A comparative analysis of Mexicans in the US and Mexico. Journal of Immigrant and Minority Health 15(3): 624-635.

Breiman, L., Friedman, J.H., Olshen, R.A., and Stone, C.J. (1984). Classification and regression trees. Belmont: Wadsworth.

Crenshaw, K. (1991). Mapping the margins: Intersectionality, identity politics, and violence against women of color. Stanford Law Review 43(6): 1241-1299. doi:10.2307/1229039.

Darmon, N., and Khlat, M. (2001). An overview of the health status of migrants in France, in relation to their dietary practices. Public Health Nutrition 4(2): 163172. doi:10.1079/PHN200064. 
Deboosere, P., and Gadeyne, S. (2005). Adult migrant mortality advantage in Belgium: evidence using census and register data. Population 60(5): 655-698. doi:10.3917/pope.505.0655.

Dubowitz, T., Bates, L.M., and Acevedo-Garcia, D. (2010). The Latino Health Paradox: Looking at the intersection of sociology and health. In: Bird, C.E., Conrad, P. and Fremont, A.M. (eds.). Handbook of Medical Sociology. Nashville: Vanderbilt University Press: 106-123.

Falter, J.-M. (2009). Le divorce, facteur de pauvreté féminine. In: Oris, M. (ed.). Transitions dans les parcours de vie et construction des inégalités. Lausanne: Presses polytechniques et universitaires romandes: 297-314.

Fibbi, R., Lerch, M., and Wanner, P. (2007). Naturalisation and socio-economic characteristics of youth of immigrant descent in Switzerland. Journal of Ethnic and Migration Studies 33(7): 1121-1144. doi:10.1080/13691830701541655.

Goldman, N., Kimbro, R.T., Turra, C.M., and Pebley, A.R. (2006). Socioeconomic gradients in health for white and Mexican-origin populations. American Journal of Public Health 96(12): 2186-2193. doi:10.2105/AJPH.2005.062752.

Hothorn, T., Hornik, K., and Zeileis, A. (2006). Unbiased recursive partitioning: A conditional inference framework. Journal of Computational and Graphical Statistics 15(3): 651-674. doi:10.1198/106186006X133933.

Hunt, L.M., Schneider, S., and Comer, B. (2004). Should acculturation be a variable in health research? A critical review of research on US Hispanics. Social Science \& Medicine 59(5): 973-986. doi:10.1016/j.socscimed.2003.12.009.

Kass, G.V. (1980). An exploratory technique for investigating large quantities of categorical data. Journal of the Royal Statistical Society. Series C 29(2): 119127. doi: $10.2307 / 2986296$.

Khlat, M., and Darmon, N. (2003). Is there a Mediterranean migrants mortality paradox in Europe? International Journal of Epidemiology 32(6): 1115-1118. doi:10.1093/ije/dyg308.

Koehn, S., Neysmith, S., Kobayashi, K., and Khamisa, H. (2013). Revealing the shape of knowledge using an intersectionality lens: results of a scoping review on the health and health care of ethnocultural minority older adults. Ageing and Society 33(3): 437-464. doi:10.1017/S0144686X12000013. 
Kohls, M. (2010). Selection, Social Status or Data Artefact: What Determines the Mortality of Migrants in Germany? In: Salzmann, T., Edmonston, B. and Raymer, J. (eds.). Demographic Aspects of Migration. Wiesbaden: VS Verlag für Sozialwissenschaften: 153-177. doi:10.1007/978-3-531-92563-9_6.

Kopf, J., Augustin, T., and Strobl, C. (2013). The Potential of Model-based Recursive Partitioning in the Social Sciences - Revisiting Ockham's Razor. In: McArdle, J.J., and Ritschard, G. (eds.). Contemporary Issues in Exploratory Data Mining in the Behavioral Sciences. London: Routledge: 75-94.

Mackenbach, J.P. (2012). The persistence of health inequalities in modern welfare states: the explanation of a paradox. Social Science \& Medicine 75(4): 761-769. doi:10.1016/j.socscimed.2012.02.031.

Markides, K.S., and Coreil, J. (1986). The health of Hispanics in the southwestern United States: an epidemiologic paradox. Public Health Reports 101(3): 253265 .

Markides, K.S., and Eschbach, K. (2005). Aging, migration, and mortality: current status of research on the Hispanic paradox. The Journals of Gerontology Series B: Psychological Sciences and Social Sciences 60: 68-75. doi:10.1093/geronb/60.Special_Issue_2.S68.

Palloni, A., and Arias, E. (2004). Paradox lost: explaining the Hispanic adult mortality advantage. Demography 41(3): 385-415. doi:10.1353/dem.2004.0024.

Powers, D.A., and Xie, Y. (1999). Statistical methods for categorical data analysis. San Diego: Academic Press.

R Core Team (2015). R: A Language and Environment for Statistical Computing. Vienna: R Foundation for Statistical Computing.

Riosmena, F., and Dennis, J.A. (2012). A tale of three paradoxes: the weak socioeconomic gradients in health among Hispanic immigrants and their relation to the Hispanic Health Paradox and negative acculturation. In: Angel, J.L., Torres-Gil, F., and Markides, K.S. (eds.). Aging, Health, and Longevity in the Mexican-Origin Population. New York: Springer: 95-110. doi:10.1007/978-14614-1867-2_8.

Ritschard, G. (2013). CHAID and earlier supervised tree methods. In: McArdle, J.J., and Ritschard, G. (eds.). Contemporary Issues in Exploratory Data Mining in the Behavioral Sciences. London: Routledge: 48-74. 
Schumacher, R., and Vilpert, S. (2011). Gender differences in social mortality differentials in Switzerland (1990-2005). Demographic Research 25(8): 285310. doi:10.4054/DemRes.2011.25.8.

Singh, G.K., and Siahpush, M. (2002). Ethnic-immigrant differentials in health behaviors, morbidity, and cause-specific mortality in the United States: An analysis of two national data bases. Human Biology 74(1): 83-109. doi:10.1353/hub.2002.0011.

Spoerri, A., Zwahlen, M., Egger, M., and Bopp, M. (2010). The Swiss National Cohort: a unique database for national and international researchers. International Journal of Public Health 55(4): 239-242. doi:10.1007/s00038-010-0160-5.

Telles, E.M., and Ortiz, V. (2008). Generations of exclusion: Mexican-Americans, assimilation, and race. New York: Russell Sage Foundation.

Therneau, T.M., and Atkinson, E.J. (1997). An introduction to recursive partitioning using the RPART routines. Rochester: Mayo Clinic, Section of Biostatistics.

Turra, C.M., and Goldman, N. (2007). Socioeconomic differences in mortality among US adults: insights into the Hispanic paradox. The Journals of Gerontology Series B: Psychological Sciences and Social Sciences 62(3): 184-192. doi:10.1093/geronb/62.3.S184.

Viruell-Fuentes, E.A., Miranda, P.Y., and Abdulrahim, S. (2012). More than culture: Structural racism, intersectionality theory, and immigrant health. Social Science \& Medicine 75(12): 2099-2106. doi:10.1016/j.socscimed.2011.12.037.

Zeileis, A., and Hornik, K. (2007). Generalized M-fluctuation tests for parameter instability. Statistica Neerlandica 61(4): 488-508. doi:10.1111/j.14679574.2007.00371.x.

Zeileis, A., Hothorn, T., and Hornik, K. (2008). Model-based recursive partitioning. Journal of Computational and Graphical Statistics 17(2): 492-514. doi:10.1198/106186008X319331.

Zeileis, A., Hothorn, T., and Hornik, K. (2010). Party with the mob: Model-Based Recursive Partitioning in R. R Package Version 0.9-9999.

Zufferey, J. (2014). Pourquoi les migrants vivent-ils plus longtemps? Analyse des différentiels de mortalité des populations suisse et étrangères 1990-2008. [PhD thesis]. Genève: Université de Genève, Faculté des Sciences de la société. 
Zufferey: The migrant mortality advantage at the intersections of social stratification in Switzerland 